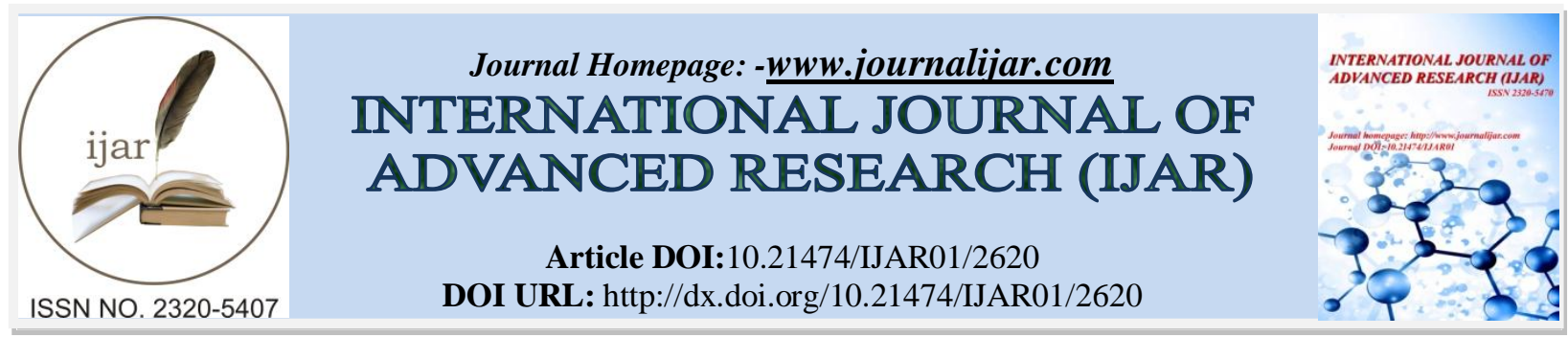

RESEARCH ARTICLE

\title{
PUBLIC AWARENESS OF RISK FACTORS AND SCREENING FOR COLORECTAL CANCER AMONG SAUDI ARABIA POPULATION, 2016.
}

\author{
"Ibrahim Ahmed Alzahrani ${ }^{1}$, Mather Jafar Alabduljabbar ${ }^{2}$, Mariam Jaber Aljehani ${ }^{1}$, Asma Mushabab \\ Alahmari ${ }^{3}$, Mohammad Mustafa Aljafar ${ }^{4}$, Ahmad Hamdan Almohammadi ${ }^{1}$ and Amal M. Ayoub Omar ${ }^{1}$. \\ 1. Medical intern, Taibah University. \\ 2. Medical intern, Ibn Sina National College. \\ 3. Medical student, Almaarefa colleges. \\ 4. Medical intern, Saudi University.
}

\section{Manuscript Info}

Manuscript History

Received: 30 October 2016

Final Accepted: 29 November 2016

Published: December 2016

\section{Abstract}

Background: Colorectal cancer is the second most common cancer in Saudi Arabia. Early screening for this disease increases the chances of successful treatment and survival. So, this study aimed to assess the level of the public awareness of risk factors and screening for colorectal cancer among Saudi Arabia population 2016, Saudi Arabia. Methods: Across-sectional study was conducted through Saudi population from all regions, including (4977) participants, of both genders and various ages. The questionnaire was answered electronically. The questionnaire consists of five main parts of questions. The first part includes demographic questions. The second part includes questions related to the awareness about the symptoms and risk factor of colorectal cancer. The third part includes questions related to the awareness of early screening for colorectal cancer. The fourth part includes questions related to Knowledge and attitude of colorectal cancer early screening. While include questions related to barrier of colorectal cancer early screening.

Results: From (4977) participants (2366) males and (2611) females, $75.8 \%$ heard about colorectal cancer before. The most symptom reported by respondents "blood with stool" by $29 \%$ only. The most risk factor reported by respondents "inflammatory and ulceration of the colon," by $32 \%$. 67\% have never heard about early screening for colorectal cancer only $5.2 \%$ do early screening for colorectal cancer. The most common known way to detect the disease "Colonoscopy". $47 \%$ do not have any reasons preventing them from having the early screening for colorectal cancer. There was a relationship between having early colorectal cancer screening and gender, age, educational level, and monthly income (P-value < 0.05). But there was a relationship between having early colorectal cancer screening and region or living place $(\mathrm{P}$-value $>0.05)$.

Conclusion:There was a low level of awareness about the symptoms and risk factor of colorectal cancer. Also, there was poor public awareness, knowledge and attitude towards colorectal cancer early screening. 


\section{Introduction: -}

Colorectal cancer (CRC) is the third most common cancer in the world, with nearly 1.4 million new cases diagnosed in 2012 and it's predicted that worldwide the number of cases will rise to 1.36 million for men and 1.08 million for woman by 2035 [2]. The community has a crucial role in increasing the awareness of the risk factors and warning signs on common diseases such as colorectal cancer. This process will provide adequate knowledge about the disease may lead the general population to involve in the cancer screening [3]. In Saudi Arabia, despite the relatively low incidence, CRC is the second most common cancer, ranking first among men (10.6\%) and third among women (8.9\%) between 1994 and 2004. In spite that KSA consider as a low-risk country for CRC, the incidence seems to be increasing with time.

The community has a crucial role in increasing the awareness of the risk factors and warning signs on common diseases such as colorectal cancer. This process will provide adequate knowledge about the disease may lead the general population to involve in the cancer screening [5].

The risk factors that are correlated with cancer most of them are avoidable, such as, sedentary lifestyles (lack of physical activity, obesity, excessive smoking and excessive alcohol), nutrition deficiency (low dietary fiber, high saturated fat intake) and infections [5]. Certain of the most important risk factors such as family history and age cannot be modified [6]. According to the data from the Saudi Cancer Registry indicate an increase in CRC incidence between 2001 an2006, and almost doubled between 1994 and 2003 [4]. Despite the increasing in the incidence of colorectal cancer, health education roles about colorectal cancer is not emphasized by Ministry of Health in compare with other cancers such as breast and lung cancer. Ministry of Health did not establish national screening program for the colorectal cancer, therefore, it's important to activate the role of health promotion and enhance the level of awareness toward colorectal cancer in the Saudi Population.

Hence, our aim of this study is to assess the level of the public awareness of risk factors and screening for colorectal cancer among Saudi Arabia population, 2016population, 2016, Saudi Arabia.

\section{Objectives: -}

- To estimate the prevalence of public awareness of early screening for colorectal cancer (CRC).

- To assess the knowledge and attitude about early screening among KSA population regarding CRC.

- To identify the Awareness of population about the symptoms and risk factor of CRC.

- To know the barrier of screening.

\section{Methodology: -}

Based on the nature of the study, and the objectives sought to be achieved, and the data to be obtained, and based on the questions that study sought to answer them, the study used descriptive analytical approach which is based on the study of the phenomenon, as it is in reality, and contribute to describe it accurately as it illustrates its characteristics through information gathering, analysis and interpretation, and then apply the results in the light.

one of this approach features that it does not stop at the end of information gathering about certain phenomenon classifying and organizing it in order to investigate different aspects of the phenomenon, but it goes to reach conclusions contribute to the understanding of reality through the analysis of the phenomenon, interpretation, and then reaching meaningful generalizations which make the study increase the credit of knowledge on the phenomenon, and contribute to the development and reality of phenomenon destination and improve it.

\section{Tool of the study: -}

The questionnaire consists of five main parts of questions. The first part includes demographic questions as (sex, age, Educational level, Region, Living location, Monthly income). And the second part includes questions related to the awareness about the symptoms and risk factor of colorectal cancer. The third part includes questions related to the awareness of early screening for colorectal cancer. The fourth part includes questions related to Knowledge and attitude of colorectal cancer early screening. While include questions related to barrier of colorectal cancer early screening.

\section{Statistical methods: -}

The statistical analysis program (SPSS v.22) was been used in the study in data entry and analysis, with the use of necessary statistical methods to achieve the objectives of the study. The following statistical methods were used:

- Frequencies. 
- Percentages.

- Diagrams.

- Chi Square test.

Population \& Sample of the Study: -

The study population includes all KSA population (31.52) million till the year of research, a sample of (4977) persons were chosen randomly, and answered the electronic questionnaire, table (1) shows their properties according to their personal data.

Table (1): Personal data for the study sample. $(\mathrm{N}=4977)$

\begin{tabular}{|c|c|c|c|}
\hline \multicolumn{2}{|l|}{ Personal Data } & Frequency & Percent \\
\hline \multirow[t]{2}{*}{ Gender } & Male & 2366 & 47.5 \\
\hline & Female & 2611 & 52.5 \\
\hline \multirow[t]{5}{*}{ Age } & Less than 18 & 330 & 6.6 \\
\hline & $19-25$ & 2240 & 45.0 \\
\hline & $26-35$ & 1425 & 28.6 \\
\hline & $36-50$ & 814 & 16.4 \\
\hline & More than 50 & 168 & 3.4 \\
\hline \multirow[t]{5}{*}{ Educational level } & Primary or less & 24 & 0.5 \\
\hline & preparatory & 103 & 2.1 \\
\hline & secondary & 1107 & 22.2 \\
\hline & Academic & 3502 & 70.4 \\
\hline & Other & 241 & 4.8 \\
\hline \multirow[t]{5}{*}{ Region } & Western region & 1423 & 28.6 \\
\hline & Eastern region & 701 & 14.1 \\
\hline & Central region & 2202 & 44.2 \\
\hline & The southern region & 376 & 7.6 \\
\hline & Northern region & 275 & 5.5 \\
\hline \multirow[t]{3}{*}{ Living location } & City & 3817 & 76.7 \\
\hline & Governorate & 844 & 17.0 \\
\hline & Village & 316 & 6.3 \\
\hline \multirow[t]{5}{*}{ Monthly income } & Less than $5000 \mathrm{rs}$ & 2420 & 48.6 \\
\hline & $5000-10000 \mathrm{rs}$ & 1180 & 23.7 \\
\hline & $10000-15000 \mathrm{rs}$ & 715 & 14.4 \\
\hline & $15000-20000 \mathrm{rs}$ & 350 & 7.0 \\
\hline & More than $20000 \mathrm{rs}$ & 312 & 6.3 \\
\hline
\end{tabular}

It is clear from the previous table that $52.3 \%$ of the participants were females, while $47.5 \%$ of them were males, most of them were in the age between (19-25) years old. And most of them had bachelor university educational levels.

It is noticed that $44.2 \%$ of them were living in the middle area of KSA, and most of them were living in the cities. And according to their monthly income; $48.6 \%$ of them had less than (5000) Riyal monthly, while $23.7 \%$ of them had from (5000-10000) Riyal monthly, and the rest of them had more incomes than mentioned. The next diagram shows that. 


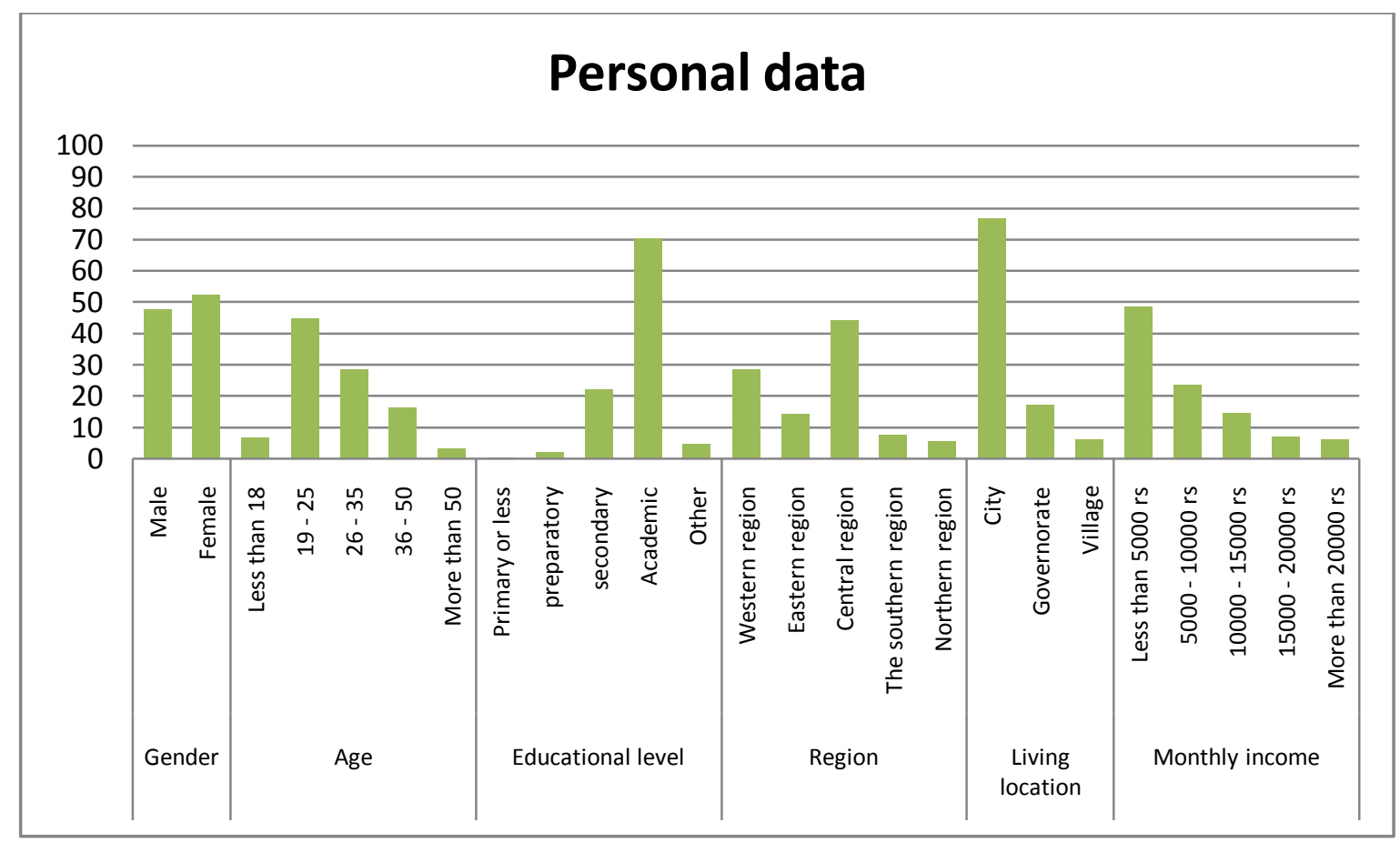

Figure (1): Personal data for the study sample.

\section{Results: -}

First: The awareness of population about the symptoms and risk factor of colorectal cancer.

The next table shows the participant's' distribution according to whether they have ever heard about colorectal cancer before or not, we notice that $75.8 \%$ of the participants heard about them before, while the others have never heard about them.

\begin{tabular}{|l|l|l|}
\hline & Frequency & Percent \\
\hline Yes & 3772 & 75.8 \\
\hline No & 1205 & 24.2 \\
\hline Total & 4977 & 100.0 \\
\hline
\end{tabular}

And the next table shows the participants' distribution according to their thought about the prevalence order of colorectal cancer; $16.4 \%$ of the participants thought that colorectal cancer are the second common tumors in KSA, while $11.9 \%$ of them thought that they are the third common tumors in KSA, and $8.1 \%$ of the participants thought that these tumors are the most common in KSA.

\begin{tabular}{|l|l|l|}
\hline & Frequency & Percent \\
\hline The first common tumors in KSA & 401 & 8.1 \\
\hline The second common tumors in KSA & 816 & 16.4 \\
\hline The third common tumors in KSA & 594 & 11.9 \\
\hline I don't know & 3166 & 63.6 \\
\hline Total & 4977 & 100.0 \\
\hline
\end{tabular}

The next diagram clarifies some of the disease symptoms, and the percentage of that the participants" thought it is really one of the symptoms or not, the most important symptom was "blood with stool" with a percentage of $29 \%$, then "quick weight loose" with a percentage of $19 \%, 14 \%$ of them thought that "stomach ache" is a symptom of colorectal cancer, and the same percentage for those who thought that "body weakness" is a symptom of the disease. 


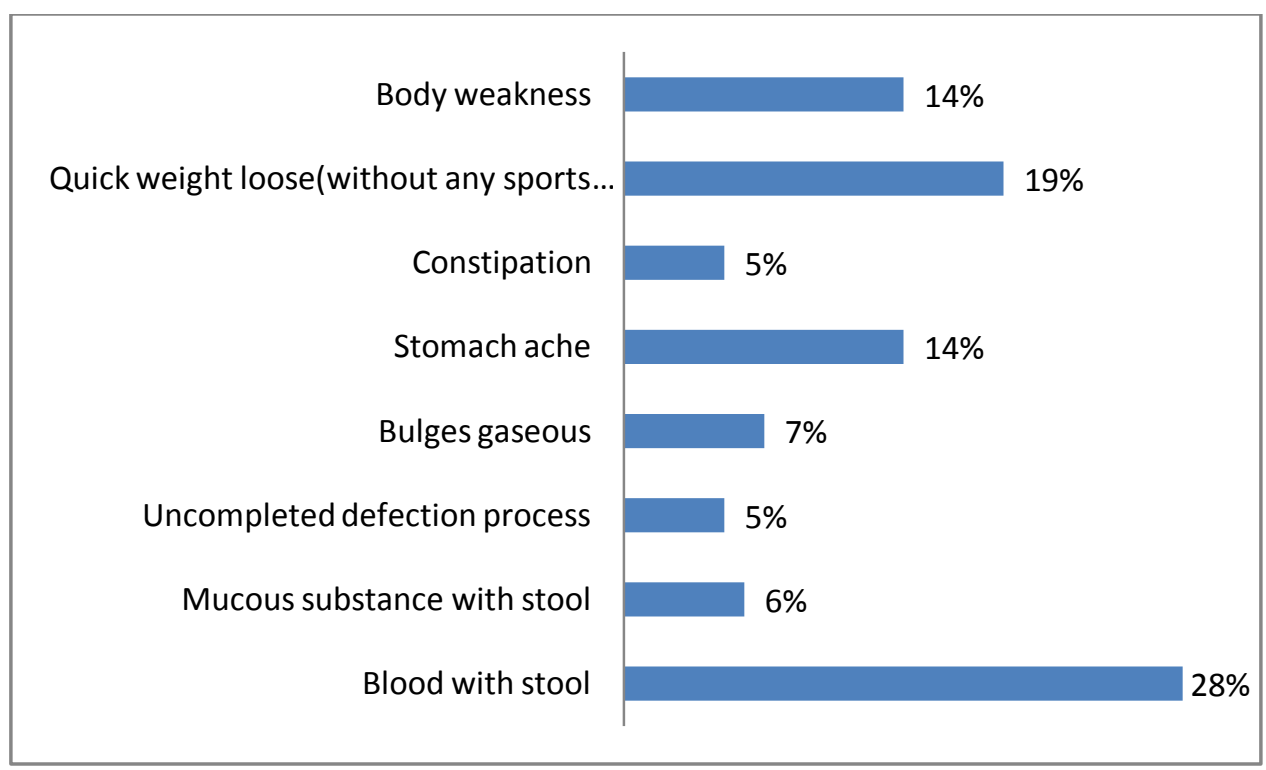

And the next diagram shows some factors that may increase the risk probability of colorectal cancer, and the proportion of respondents believe all of them; as we note that the most important of those things from the viewpoint of the participants are "inflammatory and ulceration of the colon," and "the type of food, then" a family member infected with the disease earlier ".

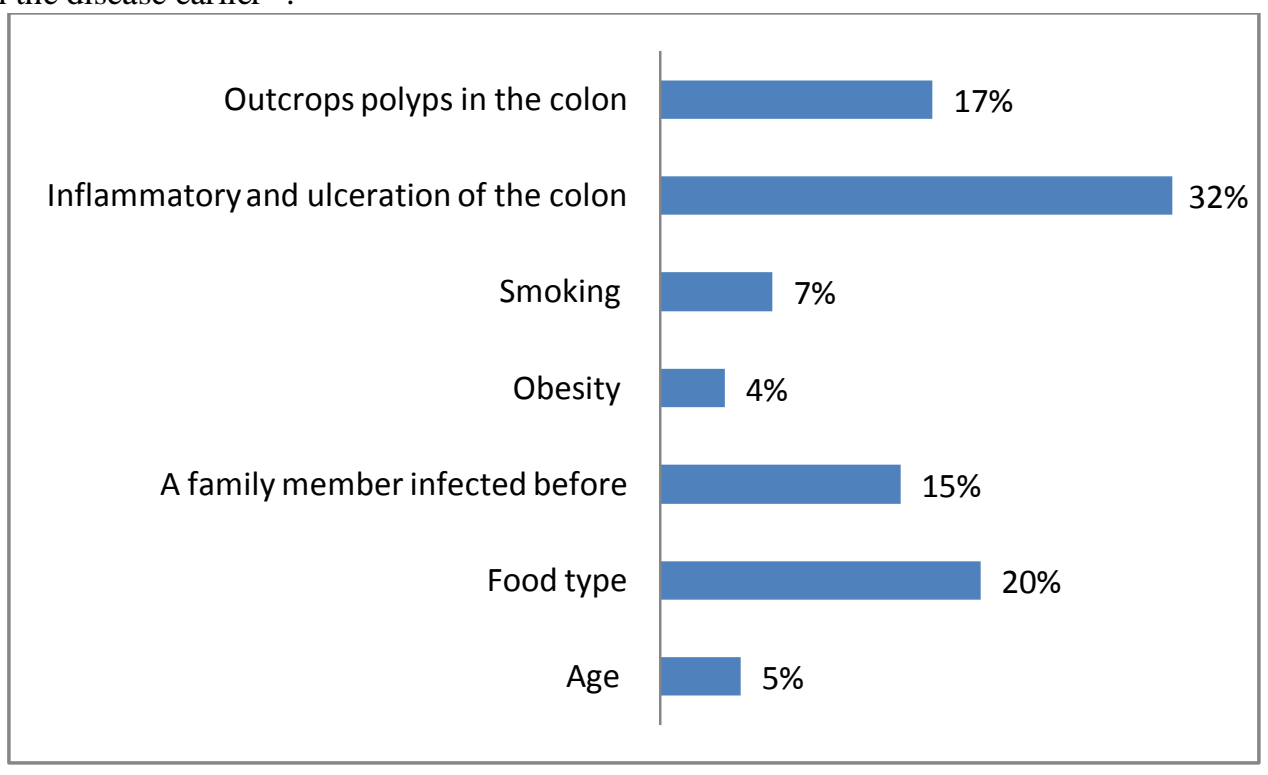

The next table shows the participants' distribution according to their belief which category is the most at risk of colorectal cancer, where we note that $29.3 \%$ thought that men are more at risk of developing this type of cancer, while $24.2 \%$ thought the equal chance of injury between the sexes in this type of cancer.

\begin{tabular}{|l|l|l|}
\hline & Frequency & Percent \\
\hline Women & 430 & 8.6 \\
\hline Men & 1460 & 29.3 \\
\hline The sexes equal proportion & 1205 & 24.2 \\
\hline I don't know & 1882 & 37.8 \\
\hline Total & 4977 & 100.0 \\
\hline
\end{tabular}

The following table we note that $49.9 \%$ of participants believe that colorectal cancer can be prevented, as well as $57.1 \%$ of participants believe that colorectal cancer can be detected early, before appearing of symptoms, and $80.4 \%$ of them believe that colorectal cancer can be treated if it is detected early. 


\begin{tabular}{|l|l|l|l|l|l|l|}
\hline & \multicolumn{2}{l|}{ Yes } & No & \multicolumn{2}{l|}{ I don't Know } \\
\cline { 2 - 6 } & $\#$ & $\mathbf{\%}$ & $\#$ & $\mathbf{\%}$ & $\#$ & $\mathbf{\%}$ \\
\hline Can colorectal tumor be prevented? & 2485 & 49.9 & 301 & 6.0 & 2191 & 44.0 \\
\hline $\begin{array}{l}\text { Can colorectal cancer can be detected early, } \\
\text { before appearing of symptoms? }\end{array}$ & 2840 & 57.1 & 465 & 9.3 & 1672 & 33.6 \\
\hline $\begin{array}{l}\text { Can colorectal cancer be treated if it is detected } \\
\text { early? }\end{array}$ & 4000 & 80.4 & 93 & 1.9 & 884 & 17.8 \\
\hline
\end{tabular}

The following table shows the source of information among participants from all previous questions about colon cancer, where $36.9 \%$ of them said that the source of that information is by the personal attention, while $31.8 \%$ of them said that the source of their information about the disease through social media and the Internet.

\begin{tabular}{|l|l|l|}
\hline & Frequency & Percent \\
\hline educational subjects & 406 & 8.2 \\
\hline Awareness campaigns & 302 & 6.1 \\
\hline personal attention & 1838 & 36.9 \\
\hline Social media and internet & 1584 & 31.8 \\
\hline By specialist explanation & 144 & 2.9 \\
\hline Friends & 703 & 14.1 \\
\hline Total & 4977 & 100.0 \\
\hline
\end{tabular}

Second: The prevalence of public awareness of early screening for colorectal cancer

The next table shows the participants' distribution according to whether they ever heard about early colorectal detection; $67 \%$ of them have never heard about that, while $33 \%$ of them have heard about that.

\begin{tabular}{|l|l|l|}
\hline & Frequency & Percent \\
\hline Yes & 1640 & 33.0 \\
\hline No & 3337 & 67.0 \\
\hline Total & 4977 & 100.0 \\
\hline
\end{tabular}

The next table shows the source from which the participants got their information about early colorectal tumor detection they heard before; social media and internet was the first source, then personal attention to know this information.

\begin{tabular}{|l|l|l|}
\hline & Frequency & Percent \\
\hline educational subjects & 223 & 13.6 \\
\hline Awareness campaigns & 289 & 17.6 \\
\hline personal attention & 470 & 28.7 \\
\hline Social media and internet & 446 & 27.2 \\
\hline By specialist explanation & 114 & 7.0 \\
\hline Friends & 98 & 6.0 \\
\hline Total & 1640 & 100.0 \\
\hline
\end{tabular}

The next diagram shows that $90.7 \%$ of the participants thought that early colorectal detection make treatment more effective. 


\section{Can early colorectal detection make treatment more effective?}

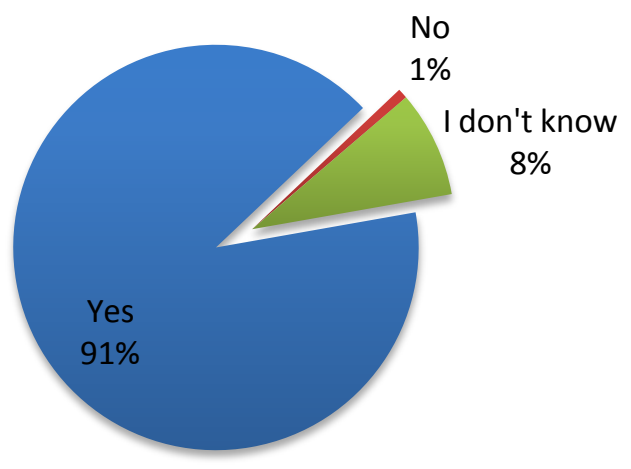

And in asking the participants about the suitable age to check for colorectal tumor, 50.1\% of the participants said that it is suitable to do the check up at (26-35) years old, while 40.1\% of them said that it is (36- 50) years old.

\begin{tabular}{|l|l|l|}
\hline & Frequency & Percent \\
\hline $26-35$ & 2494 & 50.1 \\
\hline $36-50$ & 1996 & 40.1 \\
\hline More than 50 & 487 & 9.8 \\
\hline Total & 4977 & 100.0 \\
\hline
\end{tabular}

The next diagram shows the symptoms that the participants thought it's appearance requires early colorectal tumor checkup; the most important symptoms were "blood with stool", "body weakness".

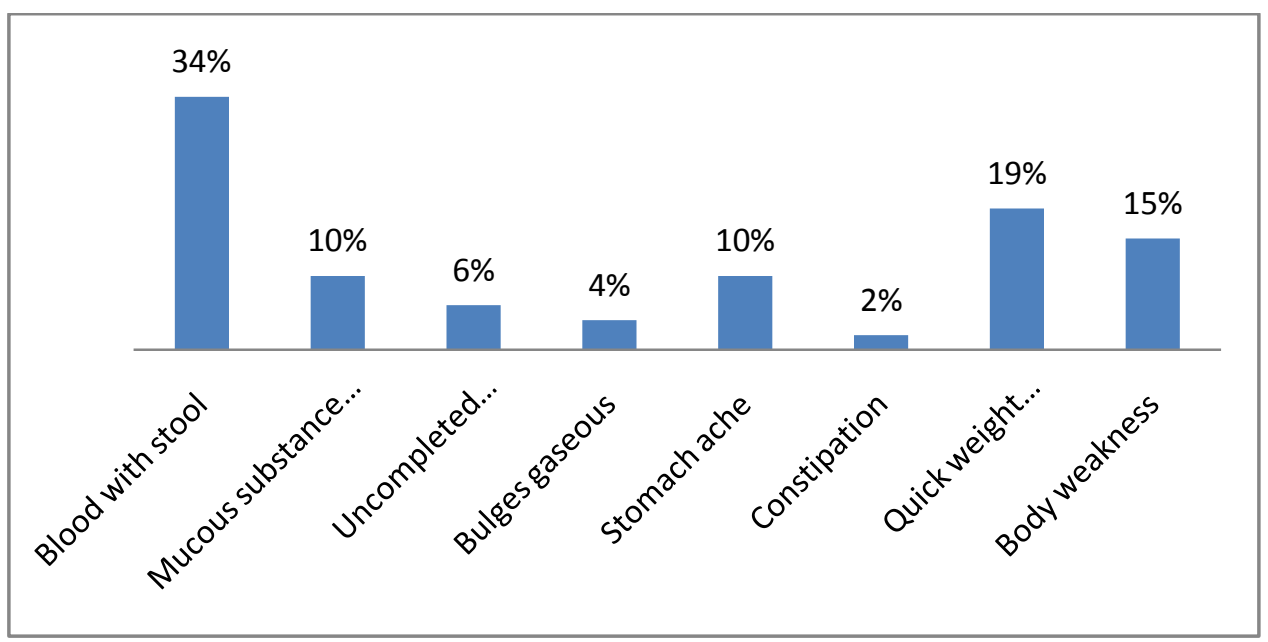

The next table shows the participants' distribution according to whether they made the early colorectal tumor checkup or not after they heard about it or advised to do that; $5.2 \%$ of them made the early checkup, while $94.8 \%$ of them didn't.

\begin{tabular}{|l|l|l|}
\hline & Frequency & Percent \\
\hline Yes & 258 & 5.2 \\
\hline No & 4719 & 94.8 \\
\hline Total & 4977 & 100.0 \\
\hline
\end{tabular}

The next table shows the participants' distribution (those who made the early checkup) according to their commitment to the checkup schedule; $40.3 \%$ were committed to the scheduled checkup, while $36.4 \%$ of them were committed randomly, and the others didn't repeat the checkup. 


\begin{tabular}{|l|l|l|}
\hline & Frequency & Percent \\
\hline In an orderly & 104 & 40.3 \\
\hline In a randomly & 94 & 36.4 \\
\hline Don't doing at all & 60 & 23.3 \\
\hline Total & 258 & 100.0 \\
\hline
\end{tabular}

The next table shows the participants' distribution according to their knowledge extent about the checkup centers in their cities; we noticethat $91.8 \%$ of them didn't know the checkup centers in their cities, while $8.2 \%$ of them knew.

\begin{tabular}{|l|l|l|}
\hline & Frequency & Percent \\
\hline Yes & 407 & 8.2 \\
\hline No & 4570 & 91.8 \\
\hline Total & 4977 & 100.0 \\
\hline
\end{tabular}

Thirdly: Knowledge and attitude about early screening among KSA population regarding CRC:

The next diagram shows some ways of early colorectal cancer detection and the participants' knowledge about these ways, we notice that the most common known way to detect the disease in KSA is "Colonoscopy" and "Screening blood in the stool sample".

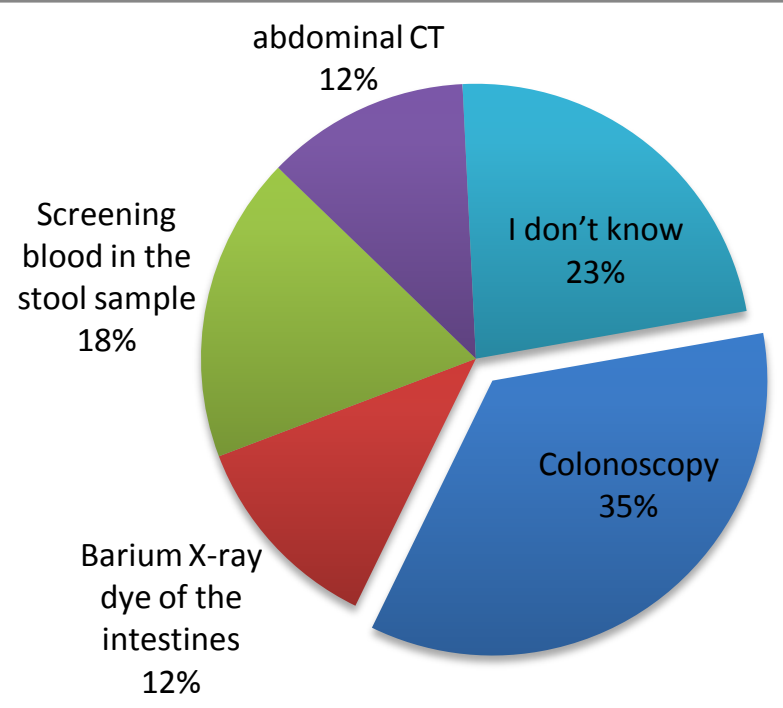

And when asking the participants about the most accurate tests; $39.8 \%$ answered "Colonoscopy", and 9.4\% barium X-dye of the intestines, while $6.9 \%$ answered abdominal CT, and 5.8\% "examining blood in a stool sample". While found $38.1 \%$ of participants have no knowledge about the most accurate tests for the detection of colorectal cancer.

\begin{tabular}{|l|l|l|}
\hline & Frequency & Percent \\
\hline Colonoscopy & 1982 & 39.8 \\
\hline Barium X-ray dye of the intestines & 467 & 9.4 \\
\hline Screening blood in the stool sample & 291 & 5.8 \\
\hline abdominal CT & 343 & 6.9 \\
\hline I don't know & 1894 & 38.1 \\
\hline Total & 4977 & 100.0 \\
\hline
\end{tabular}

And the next table shows the participants' distribution according to preferring to use a test over the others if they decide to do that; $22.2 \%$ of them would choose Colonoscopy, while $17 \%$ of them would choose abdominal CT, $16.6 \%$ would choose "Screening blood in the stool sample", and $11.2 \%$ of them would choose "Barium X-ray dye of the intestines".

\begin{tabular}{|l|l|l|}
\hline & Frequency & Percent \\
\hline Colonoscopy & 1104 & 22.2 \\
\hline Barium X-ray dye of the intestines & 559 & 11.2 \\
\hline Screening blood in the stool sample & 828 & 16.6 \\
\hline
\end{tabular}




\begin{tabular}{|l|l|l|}
\hline abdominal CT & 846 & 17.0 \\
\hline I don't know & 1640 & 33.0 \\
\hline Total & 4977 & 100.0 \\
\hline
\end{tabular}

And when they were asked about the reason for which they would choose that way for colorectal detection; $39.9 \%$ said that they did not know anything about the rest of the tests, while $23 \%$ answered because of accuracy, $21.5 \%$ for the lack of a deep intervention into the body, and $11.4 \%$ due to fear of the rest of the tests.

\begin{tabular}{|l|l|l|}
\hline & Frequency & Percent \\
\hline Accuracy & 1145 & 23.0 \\
\hline No a deep intervention into the body & 1072 & 21.5 \\
\hline Fear of the rest of the tests & 565 & 11.4 \\
\hline Speed & 209 & 4.2 \\
\hline Know nothing about the other tests & 1986 & 39.9 \\
\hline Total & 4977 & 100.0 \\
\hline
\end{tabular}

Fourth: Knowing the barrier of screening:

The next table shows the participants' distribution according to whether there were reasons prevent them from making early screening for colon cancer, where we note that $26.5 \%$ of the participants said they have reasons prevented them from conducting the examination, while $73.5 \%$ do not have any reasons preventing them from having the examination done.

\begin{tabular}{|l|l|l|}
\hline & Frequency & Percent \\
\hline Yes & 1318 & 26.5 \\
\hline No & 3659 & 73.5 \\
\hline Total & 4977 & 100.0 \\
\hline
\end{tabular}

And according to the reasons that might prevent the participants from having the required tests, the most important reasons were "the fear of the test results", and "fear of the tests" and the financial position. The next diagram shows the answers' distribution on the question.

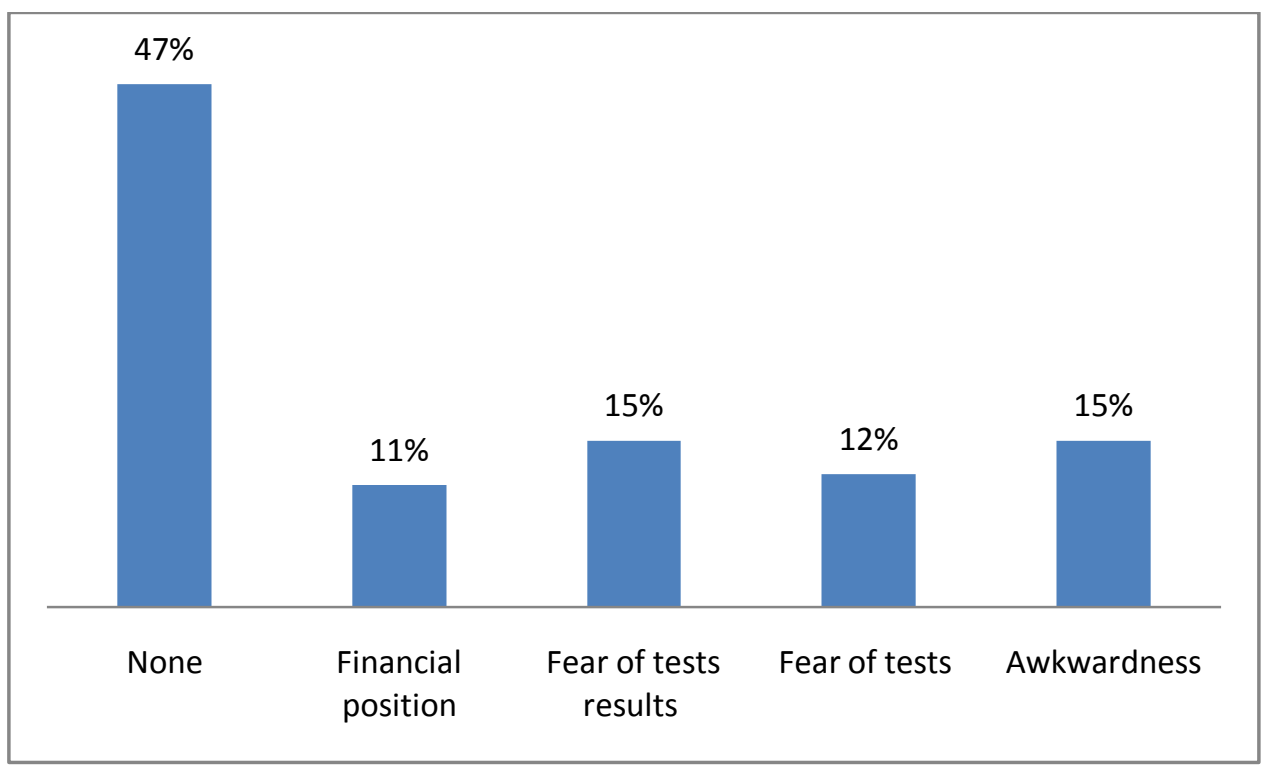

The next table shows the participants' distribution according to the reason behind the lack of an early screening for colon cancer, where we note that $35.6 \%$ of participants answered that the lack of awareness for the disease and tests is preventing them from conducting the examination, while $29.6 \%$ said that the reason behind the lack of an examination is lazing and being busy, while the others responded by other causes. 


\begin{tabular}{|l|l|l|}
\hline & Frequency & Percent \\
\hline Don't have time & 329 & 6.6 \\
\hline Lazing and being busy & 1475 & 29.6 \\
\hline I need moral / sensory incentive & 607 & 12.2 \\
\hline lack of awareness for the diseased and tests & 1770 & 35.6 \\
\hline Far health centers & 280 & 5.6 \\
\hline Other & 516 & 10.4 \\
\hline Total & 4977 & 100.0 \\
\hline
\end{tabular}

And when asking the participants if they would have the early colorectal test made if they were (obese, more than 50 years old, one of the family members was infected, smoker) even if they didn't suffer from any symptoms, $61.2 \%$ said that they would have the test made, while the others said that they wouldn't.

\begin{tabular}{|l|l|l|}
\hline & Frequency & Percent \\
\hline Yes & 3046 & 61.2 \\
\hline No & 1931 & 38.8 \\
\hline Total & 4977 & 100.0 \\
\hline
\end{tabular}

Also, when they were asked about whether they are people who have to early screening, and they have a clearer idea of early screening, will they do and advise those around them to do it? The majority of them replied that they would do so, while the remaining participants said that they wouldn't.

\begin{tabular}{|l|l|l|}
\hline & Frequency & Percent \\
\hline Yes & 4363 & 87.7 \\
\hline No & 614 & 12.3 \\
\hline Total & 4977 & 100.0 \\
\hline
\end{tabular}

Finally, when the participants were asked about the best ways to spread awareness among people about early screening for colorectal cancer, most of the answers were that the best way is through social networking sites, and awareness campaigns in public places, the curriculum and the internet, TV and others, the next diagram shows the distribution of participants' answers about each of the previous methods.

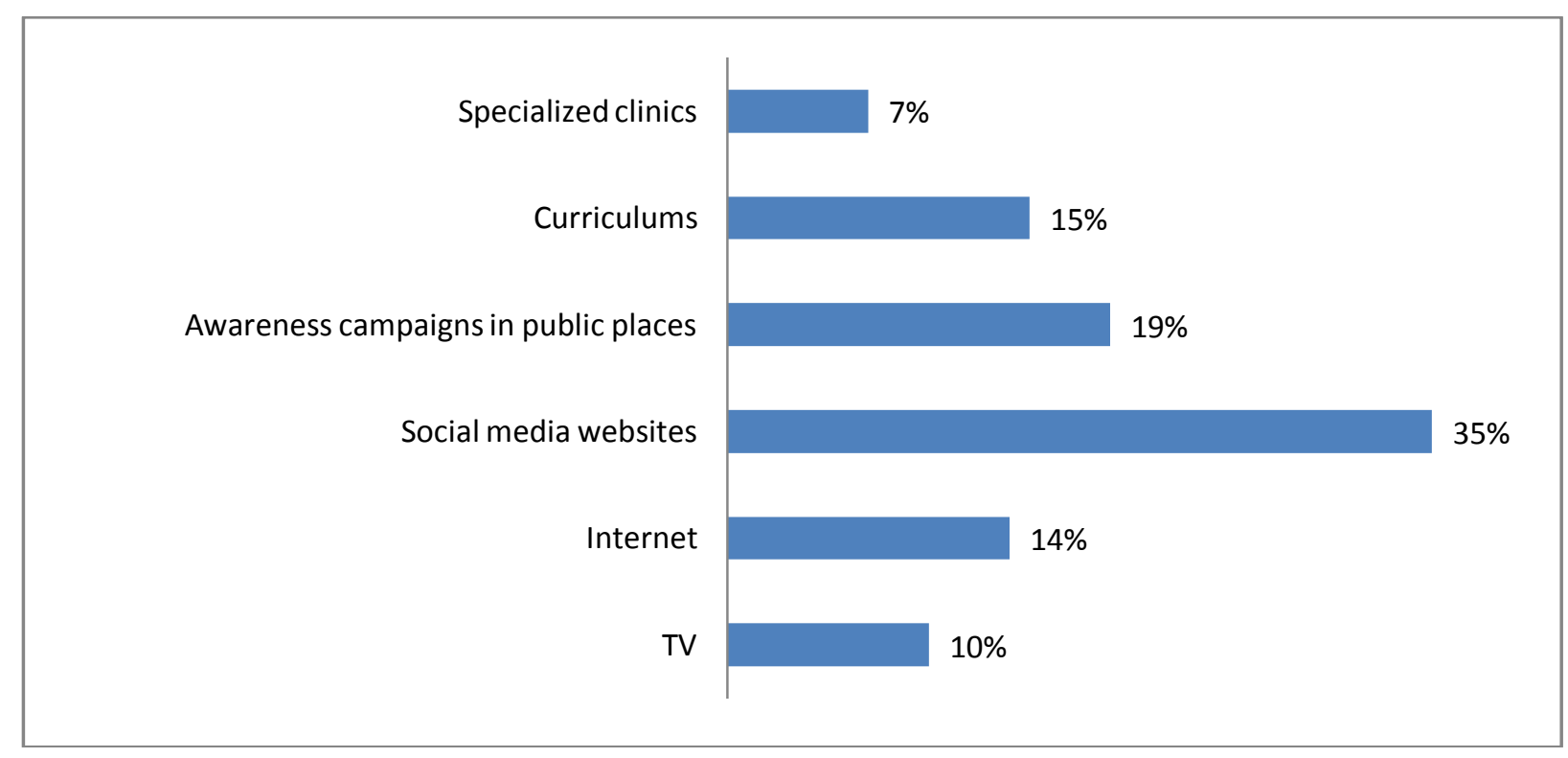

\section{Test Hypotheses:}

The next table illustrates the participants' early colorectal check extent according to their personal information. We conclude that there is a relation between sex, age, educational level, monthly income variables and the participants' early colorectal check extent, but there is no effect of the region or living place variables. 


\begin{tabular}{|c|c|c|c|c|c|c|}
\hline \multicolumn{2}{|l|}{ Variable } & \multicolumn{2}{|c|}{$\begin{array}{l}\text { Did you have the early } \\
\text { colorectal check done? }\end{array}$} & Chi-Square & P-value & Result \\
\hline \multirow[t]{2}{*}{ Gender } & Male & 138 & 2228 & \multirow[t]{2}{*}{3.862} & \multirow[t]{2}{*}{.049} & \multirow{2}{*}{$\begin{array}{l}\text { There is } \\
\text { relationship }\end{array}$} \\
\hline & Female & 120 & 2491 & & & \\
\hline \multirow[t]{5}{*}{ Age } & Less than 18 & 6 & 324 & \multirow[t]{5}{*}{97.057} & \multirow[t]{5}{*}{.000} & \multirow{5}{*}{$\begin{array}{l}\text { There is } \\
\text { relationship }\end{array}$} \\
\hline & $19-25$ & 81 & 2159 & & & \\
\hline & $26-35$ & 71 & 1354 & & & \\
\hline & $36-50$ & 69 & 745 & & & \\
\hline & More than 50 & 31 & 137 & & & \\
\hline \multirow{5}{*}{$\begin{array}{l}\text { Educational } \\
\text { level }\end{array}$} & Primary or less & 2 & 22 & \multirow[t]{5}{*}{20.109} & \multirow[t]{5}{*}{.000} & \multirow{5}{*}{$\begin{array}{l}\text { There is } \\
\text { relationship }\end{array}$} \\
\hline & preparatory & 3 & 100 & & & \\
\hline & secondary & 53 & 1054 & & & \\
\hline & Academic & 173 & 3329 & & & \\
\hline & Other & 27 & 214 & & & \\
\hline \multirow[t]{5}{*}{ Region } & Western region & 86 & 1337 & \multirow[t]{5}{*}{4.213} & \multirow[t]{5}{*}{.378} & \multirow[t]{5}{*}{ No relationship } \\
\hline & Eastern region & 39 & 662 & & & \\
\hline & Central region & 100 & 2102 & & & \\
\hline & The southern region & 19 & 357 & & & \\
\hline & Northern region & 14 & 261 & & & \\
\hline \multirow[t]{3}{*}{ Living location } & City & 207 & 3610 & \multirow[t]{3}{*}{2.648} & \multirow[t]{3}{*}{.266} & \multirow[t]{3}{*}{ No relationship } \\
\hline & Governorate & 40 & 804 & & & \\
\hline & Village & 11 & 305 & & & \\
\hline \multirow[t]{5}{*}{ Monthly income } & $<5000$ & 82 & 2338 & \multirow[t]{5}{*}{66.055} & \multirow[t]{5}{*}{.000} & \multirow{5}{*}{$\begin{array}{l}\text { There is } \\
\text { relationship }\end{array}$} \\
\hline & $5000-10000$ & 64 & 1116 & & & \\
\hline & $10000-15000$ & 40 & 675 & & & \\
\hline & $15000-20000$ & 31 & 319 & & & \\
\hline & $>20000$ & 41 & 271 & & & \\
\hline
\end{tabular}

We conclude from the next table that there is a relation between whether the person conducting early screening for colorectal cancer and the belief that cancer of the colon and rectum can be prevented, as well as a relationship between whether the person conducted the check and the extent of his belief that colorectal cancer can be detected early, before the appearance of symptoms, There is a relationship between whether the person conducting early screening and the belief that colorectal cancer can be treated if detected, and finally a relationship between whether the person conducted early screening and the belief that early screening for colon cancer and early detection gives treatment a chance to be more effective.

\begin{tabular}{|c|c|c|c|c|c|c|}
\hline \multicolumn{2}{|l|}{ Question } & \multicolumn{2}{|c|}{$\begin{array}{l}\text { Did you have the early } \\
\text { colorectal check done? }\end{array}$} & Chi-Square & P-value & Result \\
\hline \multirow{3}{*}{$\begin{array}{l}\text { Do you think that } \\
\text { colorectal cancer } \\
\text { can be prevented? }\end{array}$} & Yes & $\begin{array}{c}\text { Yes } \\
147\end{array}$ & 2338 & \multirow{3}{*}{29.199} & \multirow{3}{*}{.000} & \multirow{3}{*}{$\begin{array}{l}\text { There is } \\
\text { relationship }\end{array}$} \\
\hline & No & 31 & 270 & & & \\
\hline & I don't Know & 80 & 2111 & & & \\
\hline \multirow{3}{*}{$\begin{array}{l}\text { Do you think that } \\
\text { colorectal cancer } \\
\text { can be detected } \\
\text { early, } \\
\text { appearing before } \\
\text { symptoms? }\end{array}$} & Yes & 195 & 2645 & \multirow[t]{3}{*}{45.217} & \multirow[t]{3}{*}{.000} & \multirow{3}{*}{$\begin{array}{l}\text { There is } \\
\text { relationship }\end{array}$} \\
\hline & No & 25 & 440 & & & \\
\hline & I don't Know & 38 & 1634 & & & \\
\hline \multirow{3}{*}{$\begin{array}{l}\text { Do you think that } \\
\text { colorectal cancer } \\
\text { canbe treated if } \\
\text { detected early? }\end{array}$} & Yes & 230 & 3770 & \multirow[t]{3}{*}{22.991} & \multirow[t]{3}{*}{.000} & \multirow{3}{*}{$\begin{array}{l}\text { There is } \\
\text { relationship }\end{array}$} \\
\hline & No & 9 & 84 & & & \\
\hline & I don't Know & 19 & 865 & & & \\
\hline \multirow{3}{*}{$\begin{array}{l}\text { Do you think that } \\
\text { colorectal cancer } \\
\text { early detection gives } \\
\text { treatment a chance } \\
\text { to be more } \\
\text { effective? }\end{array}$} & Yes & 243 & 4273 & \multirow[t]{3}{*}{11.784} & \multirow[t]{3}{*}{.003} & \multirow{3}{*}{$\begin{array}{l}\text { There is } \\
\text { relationship }\end{array}$} \\
\hline & No & 5 & 34 & & & \\
\hline & I don't Know & 10 & 412 & & & \\
\hline
\end{tabular}


From the next table we conclude to that there is a relation between whether the person conducting early screening for colorectal cancer and between: the extent to hear about early screening for colorectal cancer, and the extent of his knowledge of the centers of early screening in his city, and how he believed the suitable age to perform early screening for colorectal cancer, and why he thinks it is not necessary to hold any kind of examination, while there was no relationship between whether the person conducting early screening for colorectal cancer and whether there are reasons prevented him from making an early colorectal check.

\begin{tabular}{|c|c|c|c|c|c|c|}
\hline \multirow{2}{*}{\multicolumn{2}{|c|}{ Question }} & \multicolumn{2}{|c|}{$\begin{array}{l}\text { Did you have the } \\
\text { early colorectal check } \\
\text { done? }\end{array}$} & \multirow[t]{2}{*}{ Chi-Square } & \multirow[t]{2}{*}{$\begin{array}{l}\text { P- } \\
\text { value }\end{array}$} & \multirow[t]{2}{*}{ Result } \\
\hline & & Yes & Yes & & & \\
\hline \multirow{2}{*}{$\begin{array}{lr}\begin{array}{lr}\text { Did you hear } \\
\text { about }\end{array} & \text { early } \\
\text { colorectal check? }\end{array}$} & Yes & 193 & 1447 & \multirow[t]{2}{*}{215.754} & \multirow[t]{2}{*}{.000} & \multirow{2}{*}{$\begin{array}{l}\text { There is a } \\
\text { relationship }\end{array}$} \\
\hline & No & 65 & 3272 & & & \\
\hline \multirow{2}{*}{$\begin{array}{l}\text { Do you know the } \\
\text { centers of early } \\
\text { screening in your } \\
\text { city? }\end{array}$} & Yes & 116 & 291 & \multirow[t]{2}{*}{490.310} & \multirow[t]{2}{*}{.000} & \multirow{2}{*}{$\begin{array}{l}\text { There is a } \\
\text { relationship }\end{array}$} \\
\hline & No & 142 & 4428 & & & \\
\hline \multirow{2}{*}{$\begin{array}{l}\text { are there any } \\
\text { reasons prevented } \\
\text { you from making } \\
\text { an early colon } \\
\text { cancer check? }\end{array}$} & Yes & 61 & 1257 & \multirow[t]{2}{*}{1.126} & \multirow[t]{2}{*}{.289} & \multirow[t]{2}{*}{ No relationship } \\
\hline & No & 197 & 3462 & & & \\
\hline \multirow{3}{*}{$\begin{array}{l}\text { What is the } \\
\text { suitable age to } \\
\text { perform the early } \\
\text { colorectal check in } \\
\text { your opinion? }\end{array}$} & $26-35$ & 90 & 2404 & \multirow[t]{3}{*}{46.127} & \multirow[t]{3}{*}{.000} & \multirow{3}{*}{$\begin{array}{l}\text { There is a } \\
\text { relationship }\end{array}$} \\
\hline & $36-50$ & 115 & 1881 & & & \\
\hline & More than 50 & 53 & 434 & & & \\
\hline \multirow{5}{*}{$\begin{array}{l}\text { Why do you } \\
\text { believe that there } \\
\text { is no necessity for } \\
\text { performing any } \\
\text { type of check? }\end{array}$} & Don't have time & 28 & 301 & \multirow[t]{5}{*}{13.220} & \multirow[t]{5}{*}{.010} & \multirow{5}{*}{$\begin{array}{l}\text { There is a } \\
\text { relationship }\end{array}$} \\
\hline & $\begin{array}{l}\text { Lazing and being } \\
\text { busy }\end{array}$ & 75 & 1400 & & & \\
\hline & $\begin{array}{l}\text { I need moral / sensory } \\
\text { incentive }\end{array}$ & 28 & 579 & & & \\
\hline & $\begin{array}{l}\text { lack of awareness for } \\
\text { the diseased and tests }\end{array}$ & 71 & 1699 & & & \\
\hline & Far health centers & 17 & 263 & & & \\
\hline
\end{tabular}

\section{Discussion: -}

Colorectal cancer (CRC) is the fourth leading cause of death worldwide [7]. It is well recognized that lack of cancer awareness in the community can have deleterious effects on time to presentation and, unsurprisingly therefore, on overall survival $[8,9,10,11]$. And the vast majority of cases and deaths from colorectal cancer can be prevented by applying existing knowledge about cancer prevention [12]. Therefore, this study conducted to assess public awareness of risk factors and screening for colorectal cancer among Saudi Arabia population.

The respondents showed low level of awareness about the symptoms and risk factor of colorectal cancer. The main sources of information for respondents were personal attention, followed by social media and internet. Despite its importance, awareness campaigns represent the source of information for $6.1 \%$ just. This shows the lack and dereliction of awareness campaigns related to colorectal cancer. Many previous studies showed found low levels of knowledge of CRC, including awareness of its symptoms and risk factors in many countries. In Hong Kong [13]. In West Malaysia [14]. Western Australians [15]. Iranians [16]. American Indians [17]. An ethnically diverse population in Australia [18].

At the current study, most of the respondents heard about colorectal cancer before. While $24.2 \%$ didn't hear about it before. This finding so close to study conducted by Bukhari et al., at Makah found that $23 \%$ of targeted population not hear about Colorectal cancer [19]. Colorectal cancer is the second most common cancer in Saudi Arabia [20]. 
According to our results only $16.4 \%$ reported that CRC is the second most common cancer in Saudi Arabia. While $63.6 \%$ reported that they don't know the order of colorectal cancer. This is in line with results of Bukhari et al., who's reported that 66\% not know that colorectal cancer is common in Saudi Arabia [19].

The symptoms of colorectal cancer include; rectal bleeding, change in bowel habit and abdominal pain. They may also present with systemic symptoms - anorexia, significant weight loss, fatigue and symptoms of anemia - features usually suggestive of advanced disease. In question regarding to respondents' knowledge of colorectal cancer symptoms, the most symptom reported by respondents at this study was "blood with stool" by $29 \%$. McVeigh et al., found at their study that (62\%)identified blood in the bowel motion as a worrying symptom [21]. This difference show the low level of knowledge about CRC symptoms at our study.

Colorectal cancer risk factors include; age, familial and hereditary factors, as well as environmental lifestyle-related risk factors such as physical inactivity, obesity, smoking, and alcohol consumption [12]. the most risk factor reported by responders at this study was "inflammatory and ulceration of the colon,"by 32\%. In Saudi Arabia, colorectal cancer ranking first most common cancer among men (10.6\%) and third among women (8.9\%) [20]. This perhaps because of the prevalence of smoking among men more than it among women. But in our study only $29.3 \%$ thought that men are at risk of colorectal cancer more than women.

The U.S. Preventive Services Task Force (USPSTF) and American Cancer Society strongly recommend that clinicians screen all men and women 50 years of age or older who are at average risk for colorectal cancer. The individuals who are considered at high risk because of a history of suggestive familial polyposis or hereditary nonpolyposis colorectal cancer or those with a personal history of ulcerative colitis may need to be screened earlier than age 50 [22]. In this study, there was poor public awareness knowledge and attitude about early screening for colorectal cancer. Our finding in line with Zubaidi et al., study in KSA that found there existed large knowledge gaps when it came to CRC screening, symptoms, risk factors, and detection [23]. Whereas the most of our respondents $67 \%$ had never heard about early colorectal detection. This finding confirm Bukhari et al., study in Makah fining that most respondents didn't hear about early screening of Colorectal 52\% [19]. This is considered a source of concern because the diagnosis of earlier stage disease has the potential to improve survival. The source of information about early colorectal detection at our study for the category whose heard about it was personal attention and Social media and internet, while the awareness campaigns represent the source of information for $17.6 \%$ of them. Given the awareness campaigns related to breast cancer, for example the highly successful "Pink Ribbon" campaign and the introduction of "Breast Cancer Awareness Month" annually every October has led to dramatic increase in motivation for patients to attend for screening, and have therefore resulted in an increased rate of detection of breast cancers [24]. This indicates the active role of awareness campaigns in the early screening of cancer and the need to employ it larger in relation to colorectal cancer. Although Saudi Arabia has the available resources for diagnostic and therapeutic procedures, there is lack of a consistent organized screening program for CRC screening [23].

CRC screening should be initiated at 50 years of age [23]. But according to or results only $9.8 \%$ knew that, this result similar to Alamin et al., finding by study for undergraduate students at KSA [25]. This show a low level of knowledge about CRC screening compared to other study for Greek medical students that's present majority of their participants $(83 \%)$ were able to identified the recommended age [26]. But this difference may be due to the difference in the target group at studies, the latter was belonging to medical students.

According to our results only $5.2 \%$ of the respondents had the early CRC screening after hearing about it. Less than half of this group were committed to the scheduled screening. Which means that there is a need for more effort to urge the community to make the early CRC screening. The vast majority of our respondents didn't know the CRC screening centers in their cities. This was confirmed by a study in Mecca and found that the most didn't know where the place of colorectal cancer screening is [19].

In our study the most common known way to detect the disease in KSA is "Colonoscopy", and it is the most accurate way by responders believe, the main reason for the preference of most of the respondents of this method is that they do not know anything about other screening methods. Most of our respondents do not have any reasons preventing them from having the early screening for colorectal cancer. In many of the studies reported that the financial burden is the most common obstacle of CRC screening programs [27, 28, 29]. But this does not apply to the Kingdom of Saudi where health care is publicly funded in government hospitals, in addition to a proportion of 
population being health insured. Nonetheless, access to health care facilities can be difficult due to long waiting times in public hospitals [30].

Lack of awareness for the diseased and tests were the reason of preventing one third the respondents from having the early screening. As well the majority reported that they will do the early screening if they have a clearer idea about it. And $61.2 \%$ reported that they would have this early screening if they had any of its risk factors. This close to the results of study in KSA [30], and other in Palestine [31].

According to our results there was a relationship between having early CRC screening and gender, whereas males having early screening more than females. In general, men have been more willing to participate than women [32, 33]. This could be because men are aware that lifestyle risk factors are more strongly associated with cancer in men than in women [34], or more likely reflects men's tendency to believe that cancer risk is modifiable [35]. This does not comply with another studies by Almadi et al., and Qumseya et al., found that no differences seen between males and females with regard to the willingness to undergo early CRC screening, nor was there a difference between both genders in the chosen screening method [30,31].

There was relationship between having early CRC screening and age of respondents. This is consistent with previous analysis reported by the NHIS in 2000 and $2005[32,36]$.

There was relationship between having early CRC screening and educational level. Most studies agree that CRC screening is increased in highly educated participants [37]. This is logical because it is increasing educational level is increasing awareness and then realize the need to conduct the CRC screening.

There was relationship between having early CRC screening and monthly income. One of the most important factors for predicting participation in CRC screening is socioeconomic deprivation, highlighted by the recent NHIS survey showing a progressive participation with a higher annual family income [36]. As well as economic level, may affect the level of education of individuals and hence the awareness of the importance of screening.

\section{Conclusion: -}

There was a low level of awareness about the symptoms and risk factor of colorectal cancer. As well as for $\mathrm{CRC}$,early screening there waspoor public awareness, knowledge and attitude. Awareness campaigns did not play a significant role in educating the community about CRC symptoms, risk factor, and early screening. Also, there wasn't a notable tendency to hold CRC early screening. According to our results there was a relationship between having early CRC screening and gender, age, educational level, and monthly income. But having early CRC screening didn't affected by region or living place.

\section{Recommendations: -}

- Awareness campaigns should be conducted in abundance.

- Distribution of pamphlets containing symptoms and risk factor of colorectal cancer.

- Send mobile messages containing locations of screening centers by provinces.

- Should be directed to the media to awareness about CRC.

- Urged population to maintain a balanced diet rich in fiber, do physical activity continuously, maintain a healthy weight, and avoid smoking.

- Urged population to commitment to conduct the CRC screening in a timely manner.

\section{Acknowledgements: -}

The authors would like to thank all the students and interns who participated in this study Ali Hassan Almalki, Abdullah Saib Al-Kohaji, Abdullah Mohammed Almunabhi, Mohammed Ali Al-Shammari, Mohammad Mustafa Aljafar, Abdulrahman Omar Yousef, Khaled Talal Alyami, Sultan Thani Almutrafi, Yahya Ahmed Doshi, Zahrh Abdullah Ahmed Alyousef, Maryam Mohammed Abdul ghafour Alshayook, Wigdan Mohamed Ahmed Emam Mohamed Ahmed, Jamla'a Obaid Saud Alharbi, Afaq Ali Alfaraj, Lolwah Mohammed Almustafa, Ali Salem Hmood Alhomaidh, Khalid Oqalaa Mutlaq Alshammari, Njoud Meshoweh Alewi Alenezi, Huwait Abdu Almohseen Alshammari, Rawan Ahmed Sakair, Khairiah Ahmed Al-Sumali, Abdulelah Olithah Almushdak, Ali Yahya Mohammed Maashi, Setah Rashd AlShammari, Abdullah Hassan E Aqeel, Ahmad Hamdan Almohammadi, Fatima Mohammad Hassan Alrashed, Dalal Khaled Saud Aleid, Osama Anis Jamal, Riyadh Abdullah Almalki, Mohammed 
Abdullah Al zahimah, Mohamed Ahmed Awak Khormi, Mohammed Ibrahim khan, Abdullatif Abdullah aljabri and Abdullah Heliel Aljohani for their extraordinary effort as a data collectors.

\section{References: -}

1. Ferlay J, Soerjomataram I, Ervik M, Dikshit R, Eser S, et.al; Cancer Incidence and Mortality Worldwide: IARC Cancer. IntJCancer. 2013 Mar 1;132(5):1133-45. doi: 10.1002/ijc.27711

2. International WCRF. Colorectal cancer: WCRF International. 2012. [Last cited on 2014 Jul 12]. Available from: http://www.wcrf.org/cancer_statistics/data_specific_cancers/colorectal_cancer_statistics.php

3. Su, T.T., et al., Level of colorectal cancer awareness: a cross sectional exploratory study among multi-ethnic rural population in Malaysia. BMC Cancer, 2013. 13: p. 376.

4. Ibrahim EM, Zeeneldin AA, El-Khodary TR, Al-Gahmi AM, Bin Sadiq BM.: Past, Present and Future of Colorectal Cancer in the Kingdom of Saudi Arabia Saudi J Gastroenterol 2008 Oct;14(4):178-82.

5. Su, T.T., et al., Level of colorectal cancer awareness: a cross sectional exploratory study among multi-ethnic rural population in Malaysia. BMC Cancer, 2013. 13: p. 376.

6. Sandler, R.S., Epidemiology and risk factors for colorectal cancer. GastroenterolClin North Am, 1996. 25(4): p. 717-35.

7. Ferlay, Jacques, et al. "Estimates of worldwide burden of cancer in 2008: GLOBOCAN 2008." International journal of cancer 127.12 (2010): 2893-2917.

8. Mitchell, E., et al. "Influences on pre-hospital delay in the diagnosis of colorectal cancer: a systematic review." British journal of cancer 98.1 (2008): 60-70.

9. Macdonald, S., et al. "Systematic review of factors influencing patient and practitioner delay in diagnosis of upper gastrointestinal cancer." British journal of cancer 94.9 (2006): 1272-1280.

10. Macleod, U., et al. "Risk factors for delayed presentation and referral of symptomatic cancer: evidence for common cancers." British journal of cancer101 (2009): S92-S101.

11. Richards, M. A., et al. "Influence of delay on survival in patients with breast cancer: a systematic review." The Lancet 353.9159 (1999): 1119-1126.

12. Haggar, Fatima A., and Robin P. Boushey. "Colorectal cancer epidemiology: incidence, mortality, survival, and risk factors." Clinics in colon and rectal surgery 22.04 (2009): 191-197.

13. Wong, Martin CS, et al. "The knowledge of colorectal cancer symptoms and risk factors among 10,078 screening participants: are high risk individuals more knowledgeable?." PloS one 8.4 (2013): e60366.

14. Harmy, M. Y., et al. "Knowledge and attitude of colorectal cancer screening among moderate risk patients in West Malaysia." Asian Pacific J Cancer Prev12.8 (2011): 1957-1960.

15. Christou, Aliki, and Sandra C. Thompson. "Colorectal cancer screening knowledge, attitudes and behavioural intention among Indigenous Western Australians." BMC Public Health 12.1 (2012):1.

16. Salimzadeh H, Delavari A, Montazeri A, Mirzazadeh A (2012) Knowledge and practice of Iranians toward colorectal cancer, and barriers to screening. Int J Prev Med 3: 29-35.

17. Sanderson, Priscilla R., et al. "Assessing colorectal cancer screening knowledge at tribal fairs." Prev Chronic Dis 8.1 (2011): 1-10.

18. Javanparast, Sara, et al. "Barriers to and facilitators of colorectal cancer screening in different population subgroups in Adelaide, South Australia." Med J Aust 196.8 (2012): 521-523.

19. Bukhari, Hassan, et al. "Public Awareness of Risk Factors, Screening and Prevention of Colorectal Cancer." (2010).

20. Al-Ahwal, Mahmoud S., Yasmin H. Shafik, and Hazem M. Al-Ahwal. "First national survival data for colorectal cancer among Saudis between 1994 and 2004: what's next?." BMC Public Health 13.1 (2013): 1.

21. McVeigh, Terri P., et al. "Assessing awareness of colorectal cancer symptoms and screening in a peripheral colorectal surgical unit: a survey based study." BMC surgery 13.1 (2013): 1.

22. US Preventive Services Task Force. "Screening for colorectal cancer: recommendation and rationale." Annals of internal medicine 137.2 (2002): 129.

23. Zubaidi, Ahmad M., et al. "Public awareness of colorectal cancer in Saudi Arabia: A survey of 1070 participants in Riyadh." Saudi journal of gastroenterology: official journal of the Saudi Gastroenterology Association21.2 (2015): 78.

24. Harewood, G. C., et al. "Assessment of colorectal cancer knowledge and patient attitudes towards screening: is Ireland ready to embrace colon cancer screening?." Irish journal of medical science 178.1 (2009): 7-12.

25. Alamin, Z., et al. "Assessment of the knowledge and awareness of colorectal cancer among undergraduate students in King Abdulaziz University-a survey-based study." HAMDAN MEDICAL JOURNAL 8.4 (2016). 
26. Papanikolaou, Ioannis S., et al. "Awareness and attitudes of Greek medical students on colorectal cancer screening." World J GastrointestEndosc 4.11 (2012): 513-7.

27. James, Aimee S., Christine M. Daley, and K. Allen Greiner. "Knowledge and attitudes about colon cancer screening among African Americans." American journal of health behavior 35.4 (2011): 393-401.

28. Greisinger, Anthony, et al. "Primary care patients' understanding of colorectal cancer screening." Cancer detection and prevention 30.1 (2006): 67-74.

29. Beydoun, Hind A., and May A. Beydoun. "Predictors of colorectal cancer screening behaviors among averagerisk older adults in the United States." Cancer Causes \& Control 19.4 (2008): 339-359.

30. Almadi, Majid A., et al. "Effect of public knowledge, attitudes, and behavior on willingness to undergo colorectal cancer screening using the health belief model." Saudi Journal of Gastroenterology 21.2 (2015): 71.

31. Qumseya, Bashar J., et al. "Barriers to colorectal cancer screening in Palestine: a national study in a medically underserved population." Clinical Gastroenterology and Hepatology 12.3 (2014): 463-469.

32. Seeff, Laura C., et al. "Patterns and predictors of colorectal cancer test use in the adult US population." Cancer 100.10 (2004): 2093-2103.

33. Weber, Marianne F., et al. "Population characteristics related to colorectal cancer testing in New South Wales, Australia: results from the 45 and Up Study cohort." Journal of Medical Screening 15.3 (2008): 137-142.

34. Bray, Freddie, and Wendy Atkin. "International cancer patterns in men: geographical and temporal variations in cancer risk and the role of gender." The journal of men's health \& gender 1.1 (2004): 38-46.

35. Stubbings, S., et al. "Development of a measurement tool to assess public awareness of cancer." British journal of cancer 101 (2009): S13-S17.

36. Shapiro, Jean A., et al. "Colorectal cancer test use from the 2005 National Health Interview Survey." Cancer Epidemiology Biomarkers \& Prevention 17.7 (2008): 1623-1630.

37. Gimeno Garcia, Antonio Z., et al. "Public awareness of colorectal cancer screening: knowledge, attitudes, and interventions for increasing screening uptake." ISRN oncology 2014 (2014). 